\title{
Tratamento de grave hemorragia digestiva baixa sem uso de sangue em paciente dependente de hemodiálise: relato de caso
} Treatment of severe lower gastrointestinal bleeding without the use of blood in hemodialysis-dependent patient: a case report

\author{
Walberto Monteiro Neiva Eulálio Filho¹. Helder de Melo Sérvio². \\ 1 Estudante de Medicina da Universidade Federal do Piauí, Teresina, Piauí, Brasil. 2 Cirurgião geral do Hospital de Terapia \\ Intensiva, Teresina, Piauí, Brasil.
}

\section{RESUMO}

Trata-se de um relato de caso de uma paciente Testemunha de Jeová, feminina, 66 anos, com insuficiência renal crônica dialítica, apresentou episódio de grave enterorragia e choque hemorrágico. Como a paciente recusara transfusões de sangue foram adotadas condutas alternativas para estabilização hemodinâmica. Devido a sucessivas hemodiálises apresentou queda dos níveis de hemoglobina de 7,3 g/dl no pós-operatório imediato (POI) para o valor mínimo atingido de 3,9 g/dl no $11^{\circ}$ dia pós-operatório. Permaneceu internada recebendo altas doses de eritropoietina, ferro, vitamina B12 e ácido fólico até que os níveis de hemoglobina se reestabelecessem.

Palavras-chave: Anemia. Hemorragia. Testemunha de Jeová.

\begin{abstract}
The authors report a case of a patient Jehovah's Witness, female, 66 years, with chronic renal failure requiring dialysis, she had an episode of severe intestinal bleeding and hemorrhagic shock. As the patient refused blood transfusions alternative conduits for hemodynamic stabilization were adopted. Due to successive hemodialysis decreased hemoglobin levels of $7.3 \mathrm{~g} / \mathrm{dl}$ in the immediate postoperative (IPO) for the lowest value achieved of $3.9 \mathrm{~g} / \mathrm{dl}$ in the 11th postoperative day. Remained hospitalized receiving high dose of erythropoietin, iron, vitamin B12 and folic acid until the hemoglobin level is reestablish.
\end{abstract}

Keywords: Anemia. Bleeding. Jehovah’s witness.

Autor correspondente: Walberto Monteiro Neiva Eulálio Filho, Rua Dr. José Auto de Abreu, 4020, Morada do Sol, Teresina, Piauí.Telefone: +55 86 99566-7459. E-mail: walberto@outlook.com

Conflito de interesses: Não há qualquer conflito de interesses por parte de qualquer um dos autores.

Recebido em: 02 Fev 2016; Revisado em: 15 Abr 2016; Aceito em: 22 Abr 2016. 


\section{INTRODUÇÃO}

A confissão religiosa das Testemunhas de Jeová impede que os seus praticantes recebam transfusões de sangue total ou dos seus componentes primários. Segundo esta doutrina, qualquer pessoa que se afirme cristã deverá obedecer à ordem bíblica de "abster-se de sangue", caso contrário, a vida eterna lhe será retirada.

Para os profissionais de saúde, tal recusa gera um dilema ético, particularmente em situações clínicas em que há risco de vida e onde a transfusão de sangue constituiria uma abordagem terapêutica rápida e eficaz. Este dilema acentua-se quando o doente, ao recusar a transfusão, exige tratamentos alternativos, frequentemente onerosos e de benefício duvidoso. Apresentamos um caso controverso relativo a uma doente Testemunha de Jeová com hemorragia digestiva baixa complicada de choque. ${ }^{1}$

\section{RELATO DE CASO}

Paciente Testemunha de Jeová, feminina, 66 anos, com insuficiência renal crônica dialítica, apresentou episódio de grave enterorragia e choque hemorrágico. Como a paciente recusara transfusões de sangue a mesma foi levada imediatamente a laparotomia para controle da hemorragia, ao passo que foi feita administração de soro fisiológico para evitar a evolução do choque. $\mathrm{O}$ achado cirúrgico foi de múltiplas aderências de intestino delgado terminal e sangue na luz cólon. Realizamos para o controle do sangramento enterectomia e colectomia parcial direita com ileostomia terminal e colostomia proximal. Devido a um sangramento na área cruenta por hipocoagulabilidade, foram deixadas duas compressas cirúrgicas, retiradas após 48 horas. Exame histopatológico apontou área de necrose e erosão de mucosa com infiltrado inflamatório misto e vasocongestão na parede do intestino delgado, no intestino grosso foi identificada edema e infiltrado inflamatório misto.

A paciente evoluiu séptica, anêmica com instabilidade hemodinâmica dependente de drogas vasoativas (noradrenalina e dobutamina) por 72 horas, necessitando de hemodiálise diariamente. Apresentou queda dos níveis de hemoglobina de $7,3 \mathrm{~g} / \mathrm{dl}$ no pós-operatório imediato (POI) para o valor mínimo atingido de 3,9 g/dl no 11 dia pós-operatório (DPO), seguido de um aumento lento em resposta a altas dose de eritropoietina (8000 ui a 12000 ui/dia), ferro, vitamina B12 e ácido fólico atingindo 5,1 g/dl no 19 DPO. No 20 DPO teve alta da UTI e alta hospitalar no 23 DPO (Gráfico 01).

\section{DISCUSSÃO}

O tratamento de um quadro hemorrágico consiste basicamente em duas medidas: a primeira é reposição de fluidos perdidos para manter a pressão em níveis normais e evitar o choque e a segunda é o controle da hemorragia a fim de evitar perdas futuras de sangue. Essa estratégia terapêutica tem se mostrado bastante eficaz, porém alguns pacientes por motivos religiosos se recusam a receber transfusões de sangue total ou seus derivados (plaquetas, hemácias e plasma). ${ }^{2}$
Gráfico 1. Evolução da paciente.

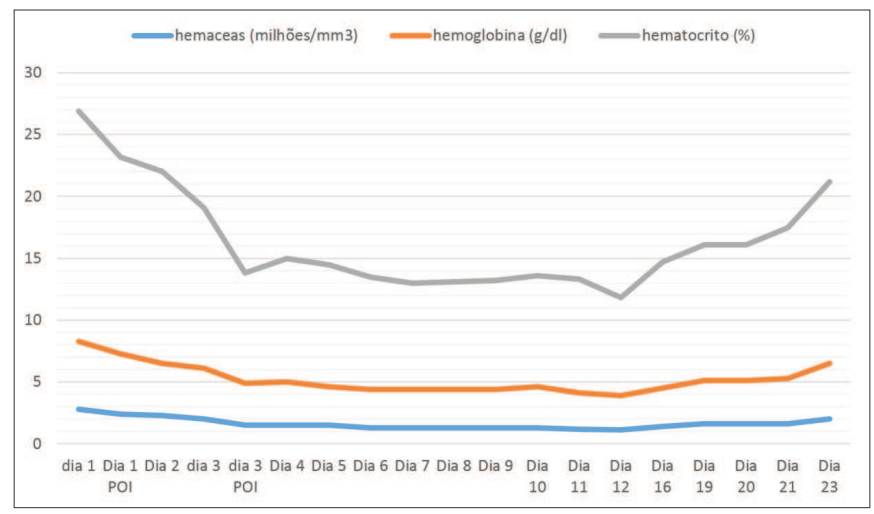

Fonte: elaborado pelos autores.

Em cirurgias eletivas, existem técnicas que podem ser utilizadas para reduzir as perdas sanguíneas durante o procedimento e que as testemunhas de jeová aceitam, devido ao fato de manterem conexão do sangue que se encontra fora do corpo com o sistema venoso do paciente. ${ }^{3}$

A primeira é a hemodiluição, esta consiste na retirada prévia de uma certa quantidade de sangue que em seguida é armazenado em uma bolsa devidamente heparinizada e conectada a um acesso venoso no paciente. Ao passo que o volume sanguíneo retirado é reposto por soro fisiológico e desse modo o sangue perdido na cirurgia tem uma menor concentração de hemácias. ${ }^{3}$

A segunda é a recuperação intraoperatória de sangue. Ela utiliza uma máquina que filtra, centrifuga, lava e armazena as hemácias que são colhidas, através de um aspirador, nas cavidades do paciente durante a cirurgia. ${ }^{3}$ Esta técnica também pode ser adaptada para colher o sangue aspirado por drenos no pós-operatório. ${ }^{4}$

No presente caso, essas técnicas não puderam ser utilizadas pois a paciente já deu entrada na urgência com hemorragia grave e em estado de choque. Como ela recusou transfusões sanguíneas foi necessário um controle imediato da hemorragia. Para tal a paciente foi encaminhada para o centro cirúrgico onde foi realizada uma laparotomia, a fim de identificar e controlar a fonte do sangramento. Também foi realizada administração de 4 bolsas de soro fisiológico para tentar repor o volume perdido e evitar o agravamento do choque hemorrágico.

Como a cavidade abdominal provavelmente estava contaminada a recuperação intraoperatória de sangue não é recomendável, visto que pode gerar uma infecção sistêmica pois, o processo de lavagem a qual as hemácias são submetidas não elimina bactérias e toxinas. Durante a cirurgia foi realizada um enterectomia e colectomia parcial direita com ileostomia terminal e colostomia proximal. Também foi deixada duas compressas cirúrgicas para controlar um sangramento. Estas foram retiradas após 48 horas.

Após a primeira cirurgia, a paciente foi encaminhada para UTI onde evoluiu séptica, utilizando drogas vasoativas por 72 
horas para controle da pressão a fim de evitar que o quadro de choque se reestabelecesse. A partir desse ponto o tratamento consistiu em elevar os níveis de hemácias circulantes. Para tal foram administradas altas doses de eritropoietina, ferro, ácido fólico e vitamina B12. Também foi utilizada oxigenoterapia via ventilação mecânica. Desse modo os níveis de hemoglobina que chegaram a $3,9 \mathrm{~g} / \mathrm{dl}$ no $11 \mathrm{DPO}$, atingiu 5,1 g/dl no 18 DPO tornando possível a alta da UTI no 20 DPO e em seguida no 23 DPO alta hospitalar com uma concentração de $6,5 \mathrm{~g} / \mathrm{dl}$.

Por se tratar de uma paciente com insuficiência renal crônica, ela realizava hemodiálise diariamente. Durante este procedimento é normal uma diminuição do hematócrito. Isso aumentou ainda mais o quadro anêmico da paciente que conseguiu ser revertido através de altas doses de eritropoietina, ferro, ácido fólico e vitamina B12. ${ }^{5}$

Nesses casos, o profissional de saúde se encontra diante de um dilema bioético. O princípio da autonomia do paciente deve sobrepujar o da beneficência? O Conselho Federal de Medicina na resolução n ${ }^{\circ}$ 1.021/80 afirma: "Em caso de haver recusa em permitir a transfusão de sangue, o médico, obedecendo a seu Código de Ética Médica, deverá observar a seguinte conduta: $1^{\circ}$ - Se não houver iminente perigo de vida, o médico respeitará a vontade do paciente ou de seus responsáveis; $2^{\circ}$ - Se houver iminente perigo de vida, o médico praticará a transfusão de

\section{REFERÊNCIAS}

1. Marques S, Carmo J, Bispo M, Barreiro P, Chagas C, Matos L. Hemorragia digestiva obscura complicada de choque em Testemunha de Jeová. GE J Port Gastrenterol. 2014;21(4):161-4.

2. Mann CM, Votto J, Kambe J, McNamee MJ. Management of the severely anemic patient who refuses transfusion: lessons learned during the care of a Jehovah's Witness. Ann Intern Med. 1992;117(12):1042-8.

3. Begliomini H, Begliomini BS. Técnicas hemoterápicas em cirurgia renal percutânea em paciente testemunha de Jeová. Rev Col Bras Cir. 2005;32(6):350-2. sangue, independentemente de consentimento do paciente ou de seus responsáveis".

No presente caso, a equipe optou por não realizar a transfusão sanguínea, pois após o controle inicial da hemorragia não se observou iminente perigo de vida durante a recuperação na UTI. A rápida intervenção cirúrgica para controle da hemorragia e a experiência dos médicos intensivistas foram fatores fundamentais para a boa evolução da paciente. Ressalta-se que diante de casos como esse é necessário que a equipe esteja preparada para realizar condutas de tratamento alternativas e atenta à evolução do paciente. Porém, uma vez que o paciente esteja em iminente perigo de vida, o profissional não deve hesitar em realizar a transfusão sanguínea.

Mediante a comprovação por escrito da vontade do doente ou de seus responsáveis, o médico deve buscar condutas terapêuticas alternativas que respeitem a decisão do enfermo. O profissional também possui o direito de não participar de um procedimento que considere moralmente errado, desde que não deixe o enfermo sem receber tratamento. Devido a isso, é fundamental que os profissionais da saúde que trabalham em serviços de urgência e emergência tenham noções da conduta que deve ser utilizada para tratar pacientes que rejeitam transfusões de sangue, ${ }^{1}$ uma vez que a vida destes não esteja em risco.

4. Gusmão LC, Valoes SH, Leitão JS Neto. Reinfusão transoperatória: um método simples e seguro na cirurgia de emergência. Rev Col Bras Cir. 2014;41(4):292-6.

5. Susantitaphong P, Alqahtani F, Jaber BL. Efficacy and safety of intravenous iron therapy for functional iron deficiency anemia in hemodialysis patients: a meta-analysis. Am J Nephrol. 2014;39(2):130-41.

\section{Como citar:}

Eulálio WM Filho, Sérvio HM. Tratamento de grave hemorragia digestiva baixa sem uso de sangue em paciente dependente de hemodiálise: relato de caso. Rev Med UFC. 2016 jul-dez;56(2):51-53. 